ISSN: 0212-0267

DOI: http://dx.doi.org/Io.I420I/hedu20I7366582

\title{
LA LABOR SOCIOEDUCATIVA \\ DE LAS MISIONES SALESIANAS \\ EN AMÉRICA Y ESPAÑA EN EL SIGLO XIX Y LOS ALBORES DEL SIGLO XX
}

\section{Socioeducative labor of the Salesian missions \\ in America and Spain in the XIX century \\ and the beginning of $X X$ century}

\author{
Vicente Llorent BedmaR \\ Universidad de Sevilla \\ Correo-e: 1lorent@us.es \\ Vicente J. Llorent García \\ Departamento de Educación \\ Universidad de Córdoba \\ Correo-e: vjllorent@uco.es
}

Dpto. de Teoría e Historia de la Educación y Pedagogía Social

Recepción: i de mayo de 20I6. Envío a informantes: 29 de julio de 2016.

Aceptación definitiva: 27 de marzo de 2017

REsumen: Este estudio pretende poner de relieve la labor inicial de las misiones salesianas, siendo una de las congregaciones religiosas más significativas desde el siglo XIX hasta la actualidad, en la historia de América y España. De esta manera resulta ineludible destacar aquellos hitos de carácter pedagógico-religioso que se fueron desarrollando en ambos territorios por orden cronológico en contextos nacionales. De tal forma que se analiza la evolución desde la llegada de los primeros salesianos a América (I874) y a España (I880), hasta inicios del siglo xx, siendo ya 3.526 y estando presentes en 3I países, más de la mitad de América. Se puede afirmar que, a causa de las distintas características históricas, económicas, políticas y culturales de España y América, la obra salesiana tiene rasgos peculiares en cada uno de estos territorios. Sin embargo, en ambos tienen un tronco común: la aplicación del sistema pedagógico preventivo y la integración sociolaboral de los jóvenes. 
LA LABOR SOCIOEDUCATIVA DE LAS MISIONES SALESIANAS EN AMÉRICA Y ESPAÑA

EN EL SIGLO XIX Y LOS ALBORES DEL SIGLO XX

VICENTE LLORENT BEDMAR Y VICENTE J. LLORENT GARCÍA

Palabras clave: historia; América; España; misiones Salesianas; historia de la educación; educación; inserción sociolaboral.

Aвstract: This study aims to highlight the initial labour of the Salesian missions, being one of the most significant religious congregations from the nineteenth century to the present, in the history of America and Spain. It is inevitable stand out their pedagogical-religious milestones, that were developed in both territories by chronological order in the different national contexts. For offering an illustration of their educational impact and social work; we must remember that, from the beginning, the Salesian were worried about the training and education of young people wherever they has spread. So we analyzes the evolution since the arrival of the first Salesians for America (I874) and Spain (I880), until the early twentieth century, still being 3526 in 3I countries, more than half of America. We can argue that the diverse historical, economic, political and cultural aspects of Spain and America, the Salesian had peculiar features in each of these territories. However, both have a common core: the application of preventive educational system and the social integration of young people.

KeY WORDs: history; America; Spain; Salesian missions; history of education; education; social and labor integration.

$\mathrm{E}$ STE ESTUDIO PRETENDE PONER DE RELIEVE la labor inicial de los salesianos, siendo una de las congregaciones religiosas más significativas desde el siglo xix hasta la actualidad, por su fomento en la inserción socioeducativa en América y España (Schwaiger, I998). De esta manera resulta ineludible destacar aquellos hitos de carácter pedagógico-religioso que se fueron desarrollando en ambos territorios por orden cronológico en contextos nacionales. Y para hacernos una idea de su impacto educativo, laboral y social debemos tener en cuenta que, desde sus comienzos, la obra de D. Bosco (I8I5-I888) se puede considerar preocupada por la formación y educación de los jóvenes allá por donde se ha extendido (Wost, 2002). La pedagogía marcada por D. Bosco se basa en la prevención, la práctica y la creatividad, estando enfocada hacia una acción educativa integral de los alumnos. Su estilo didáctico se caracteriza por combinar el trípode educativo razón, religión y amor, desde la consideración del pleno desarrollo de las capacidades de los jóvenes, resaltando su carácter vocacional y sus capacidades, buscando la adecuada conexión entre las posibilidades de cada individuo y su inserción sociolaboral (Avanzini, I990; Braido, 2010; Fierro, I949; Sinestrero, I963; Toro, 2008).

Actualmente se reconoce la labor de D. Bosco como una renovación pedagógica de la época. En sus orígenes se planteaba facilitar oportunidades educativas y sociales a niños y jóvenes desde una óptica religiosa (Bosco, 1994). Sus actuaciones pivotaban desde la educación a la evangelización. Encontrándose constantes alusiones en la obra salesiana a la perspectiva socioeducativa, refiriéndose en numerosas ocasiones a que las oraciones son necesarias, pero deben ir acompañadas 
LA LABOR SOCIOEDUCATIVA DE LAS MISIONES SALESIANAS EN AMÉRICA Y ESPAÑA EN EL SIGLO XIX Y LOS ALBORES DEL SIGLO XX

VICENTE LLORENT BEDMAR Y VICENTE J. LLORENT GARCÍA

de los hechos (Chávez, 2006; Valiente, 20II). Así a los jóvenes no se les podía contentar solo con oraciones, tenían necesidades elementales. De esta forma, D. Bosco se planteaba ayudarlos a sobrevivir y facilitarles las enseñanzas necesarias para que pudiesen valerse por sí mismos (Lenti, 20I2a; Wirth, 197I). A su vez instrumentalizaba una educación de carácter pragmático y religioso para formar «buenos cristianos», como vía para la salvación (Braido y Calonghi, I960; Nicoletti, 2005), y esto le llevó a extender su congregación por América y Europa. Este estudio se centra en el período que abarca desde sus misiones iniciales en los citados territorios hasta los albores del siglo xx. De tal forma que se analiza la evolución desde la llegada de los primeros salesianos a América (I874) y a España (I880), que aumentaron paulatinamente hasta ser 900 cuando muere D. Bosco en 1888 , hasta inicios del siglo xx, siendo ya 3.526 y estando presentes en 3i países, más de la mitad de América (Rogier, Aubert, Aubert, Bertier De Sauvigny y Knowles, 1977). Dada la dilatada extensión geográfica de su obra, nuestro estudio se centra en sus inicios por América y España para ofrecer un análisis del trabajo salesiano desde una perspectiva comparada.

\section{América}

La obra salesiana inició su expansión por Europa, si bien determinados factores influyeron en la preocupación por América. Las carencias de unas sociedadesestados incipientes, la magnitud del territorio, la ingente cantidad de inmigrantes, la presencia de indígenas y las buenas relaciones y comunicaciones con este continente provocaron la canalización de la obra salesiana hacia América.

La expansión de la educación y de la religión siempre estuvo presente en la mente de D. Bosco. Así nos percatamos cuando Juan Gazzola, cónsul argentino de Savona (Italia) en I874, coincidió con él y se interesó mucho por su obra. De hecho, el cónsul animó al arzobispo de Buenos Aires, Federico Aneyros, para que incorporara la labor de los salesianos en este país sudamericano. La decisión fue tal que el superior salesiano recibió una invitación para participar en la evangelización que el arzobispo estaba llevando a cabo en Argentina (Nicoletti, I998; Estrada, 20II). En esa época el radio de acción de la Iglesia llegaba hasta Mercedes de Patagones -limítrofe con el territorio bajo dominio indígena-, si bien por su jurisdicción le correspondía toda la Patagonia. D. Bosco aceptó el reto que le permitiría ayudar a los inmigrantes (con el insistente estímulo de los Santos Padres Pío IX y León XIII) y a los más necesitados a la vez que conseguía ver cumplidos sus sueños².

En la actualidad la Familia Salesiana está conformada por 30 grupos, que arrojan un número total de 402.500 miembros, donde hay I5.560 salesianos distribuidos en I3I países (SDB 20I2).

2 Los sueños de D. Bosco se compilaron en ig volúmenes por Giovanni Battista Lemoyne, Ángelo Amadei y Eugenio Ceria. De los 200 sueños, 6 están relacionados con la Patagonia: una fantasía con los ojos abiertos de i856; una parábola de la región de i872; vocación misional de i88i; sueño de América Meridional de I883; futuro de las misiones de 1885 , y futuro de la Congregación de 1886 (Blengino, 2005; Belza, 1982; Borrego, 1990). 
Pero no fue hasta el I4 de diciembre de i875 cuando decidió enviar los primeros diez salesianos a América. Al llegar a Buenos Aires el grupo se dividió en dos, por un lado, su responsable, Juan Cagliero, se quedó con un grupo en la capital de Argentina atendiendo a los emigrantes italianos. El resto de la expedición, comandada por Fagnano, se dirigió a San Nicolás de los Arroyos, donde fundaron un colegio, una parroquia y un oratorio, a la vez que organizaban las misiones en el campo (Hoz, 1965; Lenti, 20I2a).

\section{I.I. Primer período misionero. El inicio en las Américas}

A esta primera expedición le sucedieron otras a intervalos regulares con una clara intención pedagógico-religiosa. A continuación resaltaremos los hitos más importantes de esta fase por país siguiendo el devenir cronológico. Así, continuamos con Argentina, el primer país donde la iniciativa salesiana tuvo más facilidad para introducirse, especialmente por la gran cantidad de inmigrantes italianos y la predisposición gubernamental y eclesiástica. En noviembre de 1876 , veintitrés salesianos dirigidos por Bodrato llegaron a Buenos Aires, allí fundaron una escuela de Artes y Oficios con talleres de zapatería, sastrería, carpintería y encuadernación.

La expansión de las misiones salesianas respondía a la idiosincrasia del «Nuevo Mundo» con la constitución de sedes estables y volantes, desde donde difundir el evangelio y ofrecer una formación práctica. En el caso de Argentina, por un lado, se formaron redes que establecían un circuito desde los centros urbanos surgidos tras la conquista, además de las visitas itinerantes de los misioneros por las concentraciones rurales adyacentes. Así la tarea evangelizadora y educativa se fue distribuyendo desde Viedma y Carmen de Patagones, una como sede de Vicariato y otra como primera parroquia. Desde allí a lo largo de Río Negro (Conesa, Pringles, Choel Choel) y hacia Río Colorado y la Pampa Central (General Acha, Santa Rosa y Victorica). El itinerario costero, con Viedma como punto de origen, se extendió hasta Chubut (Rawson y Trelew), que también servía de referencia para el circuito cordillerano que cubría hasta Chos Malal. Los movimientos de la congregación llegaron hasta la Tierra de Fuego donde se fundaron misiones volantes, que tenían la tarea extra de intentar convencer a los autóctonos de los beneficios de una vida más sedentaria que evitara el nomadismo (Nicoletti y Barelli, 20ı; Valentini, 1975).

Hasta I879 los misioneros salesianos no penetraron en las regiones del interior. El I6 de abril de i879 el Gobierno argentino decide enviar una expedición militar a la Patagonia, en la que viajan varios salesianos: monseñor Espinosa, Costagma y Botta. Es el 2r de junio de este mismo año cuando comienza el trabajo salesiano con los indios pampas y tehuelches, que constituían una población de unas 80.000 personas.

Desde Buenos Aires se forma una segunda expedición que llegará el is de diciembre de I879, en apoyo de la primera. Sin embargo, la obra comenzada en este 
año no alcanzará sus objetivos hasta I883, debido a las continuas revueltas motivadas por la desconfianza de los indios y por el temor de perder su independencia, incidentes que finalizaron cuando Namuncurá, representante indígena, firmó un pacto con el ejército argentino.

Paulatinamente la labor salesiana fue en aumento, así, en I88o se instalan en Las Piedras (a 20 kilómetros de Uruguay), en i88i se desplazan a Paysandú y en I887 abren un nuevo colegio en La Plata. El general Roca, presidente de Argentina, también reconoció la obra salesiana y, según consta en la carta que éste dirigió a D. Bosco, con fecha de ıo de diciembre de i88ı, llamó a monseñor Cagliero, civilizador de la Patagonia (Martín González, 198I). En esta línea, en un escrito enviado en 1883 desde América a la Santa Sede se indicaban algunos de los logros conseguidos en esta región: 5.328 indios bautizados, dos colegios fundados y nuevas regiones internas exploradas. El 7 de diciembre de i884, cuando Cagliero fue nombrado vicario apostólico de la Patagonia, se logró la organización eclesiástica de la región ${ }^{3}$.

El 3I de octubre de i886, desde Buenos Aires partió Fagnano hacia la Isla Grande, con el objeto de explorar la zona y buscar un lugar idóneo para la futura misión, el lugar elegido fue Punta Arenas. En junio de i887 Fagnano se establece allí con tres religiosos más para trabajar con los indígenas. Y en I 888 se levantan dos misiones volantes en Isla Dawson y Cabo Peñas, además de Nuestra Señora de la Candelaria en Río Grande en 1893 (Lenti, 20I2a; Teobaldo y Nicoletti, 2007). Recordamos que las Hijas de María Auxiliadora, como sección femenina de la obra salesiana, se iban incorporando a las tareas educativo-religiosas de las distintas fundaciones, que venimos comentando (Schwaiger, 1998).

La expansión de las misiones salesianas supuso un gran impulso en la evangelización y educación de toda América del Sur; si bien las condiciones geográficas, la dispersión poblacional, la precariedad de las comunicaciones e infraestructuras y la proporción entre personal y extensión implicaron un impacto relativo (Nicoletti, 2005 y 2008), como otras congregaciones anteriormente (Coello, 2007; Nicoletti, 1998). El territorio era inmenso y con una demografía muy descompensada. Por ejemplo, el vicariato tenía una población superior a cien mil habitantes distribuidos en $730.000 \mathrm{~km}^{2}$, la prefectura contaba con menos de quince mil habitantes y una extensión de más de medio millón de kilómetros cuadrados (Estrada, 20II; Nicoletti y Barelli, 20I0).

La difusión de la obra pedagógica salesiana por América prosiguió por Uruguay, Brasil, Chile, Ecuador y Venezuela. Una parte de los miembros en Argentina se dirigieron a Montevideo, donde crearon la primera fundación uruguaya en Villa Colón, organizando el colegio Pío IX y un instituto meteorológico. El prestigio alcanzado por la orden en Uruguay fue tal que, cuando se aprobó una normativa en la que se prohibían las congregaciones religiosas en 1885 , el Gobierno

El papel de Juan Cagliero supuso una base fundamental para el desarrollo de la obra salesiana en Argentina, ganándose el sobrenombre del apóstol de la Patagonia, y siendo posteriormente el primer cardenal salesiano del Catolicismo. Para ampliar sobre su vida consultar EnTRaigas (I955). 
LA LABOR SOCIOEDUCATIVA DE LAS MISIONES SALESIANAS EN AMÉRICA Y ESPAÑA EN EL SIGLO XIX Y LOS ALBORES DEL SIGLO XX VICENTE LLORENT BEDMAR Y VICENTE J. LLORENT GARCÍA

renunció a tomar medidas contra los salesianos por su insustituible aportación educativa (Cantero, 1958; Lemoyne y Fierro, 1957).

En cuanto a Brasil, el obispo de Río de Janeiro, monseñor Lacerda, durante una visita a Turín en 1877 , comunica a D. Bosco la necesidad de enviar salesianos al citado país americano, para evangelizar a las tribus de las selvas ecuatoriales y para instruir a una juventud que se había beneficiado de la Ley de emancipación de los hijos de esclavos (Schlossarek, 2006; Saranyana, 2008). Al carecer de suficiente personal, esta demanda no pudo ser atendida hasta i882, con la llegada de Lasagna ${ }^{4}$, quien en I883 abre la primera casa salesiana en Nieroi. Más tarde le siguen la de São Paulo (I885) y la de Lorena (1890)'

En Chile se inició la labor socioeducativa salesiana con un oratorio, talleres y escuelas en 1877. Después de algunas dudas, motivadas por la falta de personal, se formó un grupo de salesianos, que el 6 de diciembre de 1877 partió para Ecuador. Esta expedición llegó a Quito el 28 de enero de I888. La noticia tuvo tanta repercusión que llegó hasta España antes de que transcurriera un mes. El cónsul de la República de Ecuador en España, Francisco Bravo y Liñán, se expresaba con las siguientes palabras «Con vivo interés supe por mi gobierno el contrato celebrado por el Ilmo. Sr. Arzobispo de Quito y el Pro. Juan Bosco, y la propia ida de los P.P. Salesianos al Ecuador» (Carta de Bravo y de Liñán fechada en Sevilla a I4 de febrero de i888).

En Venezuela durante el mandato de Joaquín Crespo (I884-I886) se mejoraron las relaciones con la Iglesia católica, permitiéndose la creación de la Asociación Liga de Cooperadores Salesianos, fundamental en la divulgación de la obra de D. Bosco y la fundación del Centro Católico Venezolano (Toro, 2008).

\section{I.2. Segundo período misionero, después de la muerte de D. Bosco}

Tras la muerte de D. Bosco (I888) la obra misionera se interrumpió hasta I890, año en que los salesianos se instalaron en Caracas, donde ocuparon una ya existente escuela de formación profesional (Colegio León XIII) y se destacaron por su trabajo con los leprosos. En Caracas en i894 y en Valencia (Venezuela) en i895 se establecieron nuevas fundaciones salesianas con tareas educativas.

En 189i se instalan en Lima (Perú), fundando un oratorio y una escuela profesional para niños pobres. En I897 y I898 se crearon nuevas casas en Arequipa y en Callao. Los salesianos llegaron a Cuzco y Piura en 1905 y 1906 respectivamente.

En México fundaron una escuela de formación profesional en I892, para más tarde extender su labor por otras ciudades mexicanas, entre las que se encontraban Puebla, Morelia y Guadalajara.

4 Luis Lasagna llegó a las misiones en la segunda oleada salesiana en I876, empezando en Uruguay y luego Brasil. En I893 fue ordenado obispo y centró su trabajo en la evangelización de los indígenas a petición del papa León XIII.

Ciertamente en aquella fecha (I882) también se recibieron propuestas para llevar la obra salesiana a Boston. Pero los compromisos adquiridos en Europa y América del Sur le impidieron aceptar de inmediato, siendo en 1945 cuando se fundó la D. Bosco Technical High School. 
LA LABOR SOCIOEDUCATIVA DE LAS MISIONES SALESIANAS EN AMÉRICA Y ESPAÑA EN EL SIGLO XIX Y LOS ALBORES DEL SIGLO XX

VICENTE LLORENT BEDMAR Y VICENTE J. LLORENT GARCÍA

El comienzo de la obra salesiana en Bolivia se debe a las manifestaciones realizadas por su presidente, Aniceto Arce, en I890, en las que mostraba su interés por que los salesianos abrieran una escuela de formación profesional en su país. Pero no será hasta el I7 de febrero de I896 cuando lleguen los primeros salesianos; que tras crear dos colegios se encontraron con un reto singular, que no era otro que el elevado número de indios que pretendían recibir clase, por lo que se tuvieron que crear secciones especiales para ellos. En 1896 los salesianos fundan una escuela de artes y oficios en Asunción (Paraguay) (Lenti, 20I2a).

Su primer contacto con América Central se produjo a finales de i897 en El Salvador, donde crearon una escuela profesional agrícola y un orfanato en Curasao.

En EE. UU. las actividades salesianas, que se desarrollaron entre I897 y 1902, tuvieron como finalidad inmediata ayudar a los emigrantes italianos. En San Francisco organizaron clases nocturnas de inglés, crearon un secretariado del pueblo con el fin de encontrar trabajo para los recién llegados y buscar alojamientos a los huérfanos y editaron un semanario: L'italiano in America.

Volviendo a países donde los salesianos iniciaron su labor, debemos resaltar nuevos hitos que denotan la consolidación y permanente expansión de su presencia. En Argentina, transcurridos veinticinco años de la llegada de los salesianos a Buenos Aires, el número de casas salesianas alcanzaba la cifra de 250 y no dejaba de aumentar en I900. En I905 se fundó una nueva casa en Córdoba, una escuela agrícola en Rodeo del Medio y un nuevo oratorio en Buenos Aires.

Este mismo incremento se repite en Uruguay durante el período que va desde I893 a I895, creando nuevos colegios en Paysandú y Mercedes, y una escuela profesional en Montevideo.

En Brasil el cambio de régimen político, originado tras la revolución de I889, no tuvo consecuencias negativas para los salesianos, por lo que prosiguieron con su labor de expansión. En 1890 crean una nueva fundación en Lorena y en I897 una casa en Campiñas.

En Chile la obra salesiana sufrió en sus orígenes las consecuencias de la guerra civil. Una vez finalizada, Tomatis, el director salesiano, creó escuelas, oratorios y talleres, e incluso se adentró en regiones no exploradas para evangelizar a los indios araucanos. Esta labor fue altamente valorada por el pueblo y por los sectores políticos, de forma que el propio jefe del partido socialista invitó a la Cámara, a través de un escrito fechado el I6 de agosto de 1937, a adherirse a los honores que se iban a tributar a la Congregación Salesiana (Lemoyne y Fierro, 1957: 616):

No se debe olvidar que de los 30.000 habitantes de Magallanes, la Antigua Punta Arenas, la mitad recibieron instrucción de los salesianos, quienes con sus escuelas, talleres y granjas, civilizaron esas regiones semibárbaras.

En I893 el Gobierno chileno permitió el establecimiento a Fagnano en la isla de Tierra de Fuego durante veinte años para que los salesianos evangelizaran e instruyeran a los indígenas. En ella se creó la misión de la Candelaria y se instruyó a los indios onas, enseñándoles a construir escuelas y dispensarios, así como a cultivar la tierra, a criar ganado y a realizar ciertas labores domésticas. 
En este segundo período, fue especialmente dura la labor salesiana en Ecuador. Fueron numerosas las ocasiones en las que los indios jíbaros incendiaron las construcciones de la orden, hasta que Albera, en 1902, consiguió calmar su carácter belicoso (Nicoletti, 2008).

\section{I.3. Apuntes sobre el trato con indígenas}

En general, los salesianos hicieron uso de las lenguas de los indígenas para la circulación de sus discursos religiosos, intentando homogeneizar sus doctrinas. Desde un punto de vista educativo la comunicación efectiva era necesaria para desarrollar una pedagogía preventiva (Alberdi, I994; Braido, 20Io; Braido, Simoncelli, Gianola y otros, 1957; Valiente, 20II). Ciertamente utilizaban términos en español para evitar derivaciones e interpretaciones, y de esta manera conservar la universalidad del mensaje cristiano. Evidentemente los misioneros buscaban las traducciones más oportunas con el ánimo de encontrar nexos de unión con la cultura indígena y así nutrirla de los nuevos conceptos católicos, recategorizando los principios de la religión indígena. Esta combinación multicultural -si bien partía del respeto por los indígenas como personas iguales, con diversidad lingüística y con unas prácticas idólatras diferentes- tendía a la paulatina imposición de la lengua española y del cristianismo (López Torres, 2oIr y Nicoletti y Barelli, 20IO).

Los salesianos, que entendían la unicidad de los seres humanos y la igualdad de derechos, no podían evitar su concepción etnocéntrica donde, desde un supuesto evolucionista, los autóctonos americanos se encuentran en un peldaño evolutivo por debajo de los europeos (Nicoletti, 2006 y 2007). De tal manera que (Nicoletti, 2004: 154) D. Bosco y sus misioneros entendían que los indígenas debían ser educados y evangelizados para que su nivel de civilización pudiera llegar al nivel del resto.

Así la educación y la evangelización difundida por los salesianos lograrían desarrollar esta situación, de hecho se entienden como instrumentos fundamentales para el progreso social y para la perfección de su moral, camino ineludible para el buen ciudadano y el buen cristiano (Schwaiger, 1998).

\section{España}

Continuamos con la expansión salesiana en España que, tras Italia, era el país europeo con mayor aceptación y actualmente con más hermanos de la congregación. En un primer momento se analiza el centro pionero en España de la presencia salesiana, Utrera (Sevilla), para luego comentar su difusión en otras localidades y la consolidación de la congregación. 
LA LABOR SOCIOEDUCATIVA DE LAS MISIONES SALESIANAS EN AMÉRICA Y ESPAÑA EN EL SIGLO XIX Y LOS ALBORES DEL SIGLO XX

VICENTE LLORENT BEDMAR Y VICENTE J. LLORENT GARCÍA

\section{I. Primera Fundación: Utrera}

Los primeros salesianos enviados por D. Bosco a España llegaron a Utrera a petición de Joaquín Lluch y Garriga, arzobispo de Sevilla, quien había comunicado a D. Bosco el deseo del marqués de Casa-Ulloa ${ }^{6}$, fundar una casa para los niños huérfanos de Utrera. En una carta firmada por el mencionado marqués y fechada el 6 de junio de 1879 en Sevilla, puede confirmarse como él mismo se hace cargo de los gastos de la congregación para este fin durante cuatro años (Alberdi, 1994).

Ese mismo año de 1879 D. Bosco contestó al escrito del arzobispo, comunicándole la llegada de los salesianos en el mes de octubre. Pero la escasez de personal y las numerosas peticiones que le llegan desde América, como hemos expuesto antes, hacen que se posponga hasta finales de i88o, cuando el director de la Sociedad San Francisco de Sales consigue reunir 20 religiosos, de los cuales I4 se dirigen a Argentina y 6 a España.

La llegada de los salesianos a España, y con ello el inicio de su obra en nuestro país, se produce en Utrera el día i6 de febrero i88o a las seis y media de la tarde; el pequeño grupo estaba formado por Juan Branda, Ernesto Oberti, Carlos Pane, Francisco Atzeni, Miguel Aranda y José Goitre.

De todos los salesianos enviados por D. Bosco, sólo Juan Cagliero sabía hablar español, lengua que seguramente había perfeccionado cuando dirigió la primera expedición salesiana a Buenos Aires, como hemos comentado en el apartado anterior. Fue éste uno de los motivos por los que el superior de la orden puso en sus manos la difusión de la obra salesiana en España (Martín González, 198I).

El quehacer salesiano ya era conocido en España antes de la llegada de los salesianos. A este respecto, Ramón Lluch y Garriga ya había editado en la Revista Diocesana de Sevilla la «Historia del Oratorio» y publicaciones similares se habían difundido en diversas revistas de Madrid y de Barcelona. Este hecho sorprende a Cagliero, quien escribió desde Sevilla a D. Bosco notificándoselo: «... y así somos conocidos perfectamente por montes y mares de esta Península Ibérica» (Carta de Cagliero a D. Bosco: Sevilla 23 de febrero de I88I).

En abril de i88ı, y una vez encauzada la labor salesiana en España, Juan Cagliero dejó Utrera y se dirigió a Tierra de Fuego ( $c f$. Gómez Bajuelo: I0-7-I930). Un año más tarde, en abril de i882, bajo la dirección de Juan Brada se creó en Utrera la escuela de San Diego, quien nos relata así sus comienzos (Archivo de la casa de Utrera: 4 y 5):

... en el mes de abril (en la calle Ancha) se abrieron escuelas diurnas para los pequeños y nocturnas para los mayores. A fines de 1882 (ya en el Carmen) fueron hospedados -como internos- varios niños pobres.

En los primeros tiempos las Escuelas Elementales de San Diego contaron con unos 130 alumnos, pero pronto este número aumentó a 400. El sistema pedagógico Sevilla.

Santiago Calvo de la Banda y Aragón, cuya descendencia y familia siguen en la provincia de 
LA LABOR SOCIOEDUCATIVA DE LAS MISIONES SALESIANAS EN AMÉRICA Y ESPAÑA

EN EL SIGLO XIX Y LOS ALBORES DEL SIGLO XX

VICENTE LLORENT BEDMAR Y VICENTE J. LLORENT GARCÍA

aplicado en estas escuelas era muy parecido al llevado a cabo en el Oratorio (Escuelas salesianas de Turín). Por las mañanas asistían a misa, a sesiones de escritura, lectura y cálculo; las tardes las dedicaban a juegos, catequesis, canto, teatros, proyecciones, tómbolas, etc.

Los éxitos de la obra salesiana comenzaron a extenderse por toda España con tal intensidad que el propio rey Alfonso XII felicitó a Juan Brada, y el partido liberal se declaró defensor de aquellos «educadores del pueblo utrerano».

El I6 de febrero de i885, cuando se cumplían cuatro años de permanencia salesiana en Utrera, la comunidad se planteó la posibilidad de abandonar esta localidad, para establecerse en otra ciudad más populosa.

Por entonces la comunidad salesiana tenía planteados dos serios problemas: la falta de personal, ya que parte de la comunidad estaba en Málaga atendiendo el asilo de San Bartolomé, y la insuficiencia de recursos económicos con los que contaba para mantener abiertas las Escuelas Populares de San Diego. Se barajaron dos alternativas: la primera significaría trasladar la comunidad de Utrera a Madrid, a la vez que aceptaban la dirección del Reformatorio de Carabanchel Bajo, y la segunda consistía en construir un colegio de educación secundaria, para que, a través de sus ingresos, se pudieran sostener de forma estable las escuelas gratuitas. Esta última propuesta fue defendida por el marqués de Casa de Ulloa, en una carta dirigida a D. Bosco, donde se puede leer en la carta de 2I de noviembre de I885 (De Santiago, I885):

Y después de poner en manos de Dios nuestro deseo, y de consultarlo D. Oberti con sus superiores, me manifestó que si se aplicara el local para poder recibir unos 200 internos, se podría establecer un colegio de módica pensión para las modestas fortunas de la clase media y de la clase trabajadora.

Dicho asunto se trató en la sesión del 9 de enero de I885 del Consejo Generalicio, en Turín, en la que D. Bosco accedió a la ampliación del colegio, en contra de la postura adoptada por Cagliero, que pensaba que esta decisión iba a suscitar envidias y hostilidades contra la orden.

Una vez solucionado este problema, en octubre de i886, se abrieron las «clases de pago» para alumnos de primera y segunda enseñanza. A partir de entonces el colegio de Utrera se estabilizó, y, posteriormente, experimentó una nueva ampliación, patrocinada por el senador Miguel Muruve.

El número de alumnos iba en aumento y se realizaban nuevas obras en el colegio. En 1927 el colegio contaba con 32r alumnos internos, 95 externos y 425 niños del pueblo, estos últimos de forma gratuita.

Las condiciones que en 1934 tenía el recinto escolar fueron descritas por Gómez Bajuelo (1934), periodista y antiguo alumno de dicho centro:

Suntuoso edificio, de magníficas aulas, espaciosos dormitorios abiertos al campo, extensos patios de recreo, gabinetes científicos dotados de los más modernos elementos, un gran teatro, galerías de duchas, baños, etc. 
LA LABOR SOCIOEDUCATIVA DE LAS MISIONES SALESIANAS EN AMÉRICA Y ESPAÑA

EN EL SIGLO XIX Y LOS ALBORES DEL SIGLO XX

VICENTE LLORENT BEDMAR Y VICENTE J. LLORENT GARCÍA

\subsection{La obra salesiana se extiende al resto de España}

En I882, dos años después del inicio de la obra salesiana en Utrera, el arzobispo de Málaga propone a los salesianos que se hagan cargo del asilo de niños huérfanos de San Bartolomé (Málaga), a esta solicitud responde de forma afirmativa la congregación.

El 20 de septiembre de aquel año Dorotea Chopitea de Serra escribía la primera carta a Turín solicitando la apertura de un centro salesiano en los alrededores de Barcelona. Volvió a insistir precisando que el propósito era contribuir a fundar un establecimiento de artes y oficios, subrayando que Barcelona era en España lo que Lyon y Marsella en Francia, una ciudad industrial y mercantil, siendo un lugar adecuado para desarrollar la labor salesiana. En i885, Dorotea Chopitea de Serra finalmente consigue que Juan Branda, director de la casa de Utrera, se dirigiera a la Ciudad Condal con la mitad de la comunidad salesiana de Utrera; en el mes de marzo del mismo año se inauguraron los Talleres Salesianos de Sarriá, denominados Talleres Salesianos del Niño Jesús (Lenti, 2oıra; Martínez Azcona, Calero y otros, 1980).

El 8 de abril de I886, D. Bosco visitó Sarriá y la casa salesiana de Barcelona para supervisar su funcionamiento, y fue tan grata su impresión que eligió a esta ciudad como casa central de los salesianos en España. Inmediatamente se impulsó la apertura de la escuela tipográfica considerada la primera de España. Con el apoyo económico de Dorotea y de otros cooperadores se pudo ampliar la casa de Sarriá, ofreciendo cinco áreas de especialización de los talleres, así también se pudieron articular otros órganos como el colegio del Santo Ángel de primera enseñanza, el aspirantado-noviciado para la formación de futuros salesianos y la iglesia de María Auxiliadora (Alberdi, 1994).

A partir de este momento la obra salesiana adquiere una inusitada dinámica de ampliación. En I89o se inaugura el nuevo colegio de San José de la calle Rocafort y el Oratorio Festivo, en I89I se crean la Escuela Agrícola de San Isidoro en Gerona y en I892 el Oratorio Festivo y las Escuelas Populares en Santander (Bastarrica, I98I).

Bajo la dirección de Felipe Rinaldi, delegado salesiano en España durante diez años (1892-I902), y una vez abiertas las cinco primeras casas salesianas, se instituye la primera Inspectoría Salesiana en España.

Durante el mandato de Rinaldi se multiplican las casas salesianas: SevillaTrinidad (1892, donde surgen una escuela profesional y un colegio de educación secundaria), Vigo (I892), Rialp (I893), Málaga (1894), S. Vicenç dels Horts (I895), Béjar (I896), Carmona y Baracaldo (1897), Montilla (Córdoba) y Madrid-Atocha (I899). Así también sucedía con las escuelas profesionales fundándose en Barcelona-Sarriá (1884), Sevilla (1894) y Málaga (I897).

De especial importancia para la congregación salesiana es el año i893, pues fue entonces cuando Rinaldi consiguió el reconocimiento oficial de los centros salesianos por parte del Estado Español (Lenti, 20I2b).

Cuando Rinaldi tuvo que volver a Italia en I902, España contaba con veintiuna casas, ciento noventa y cinco salesianos profesos y setenta y nueve novicios. 
LA LABOR SOCIOEDUCATIVA DE LAS MISIONES SALESIANAS EN AMÉRICA Y ESPAÑA EN EL SIGLO XIX Y LOS ALBORES DEL SIGLO XX VICENTE LLORENT BEDMAR Y VICENTE J. LLORENT GARCÍA

La Península Ibérica quedaba dividida en cuatro inspectorías, una portuguesa y tres españolas, estas últimas eran: Inspectoría Bética de María Auxiliadora, su sede se encontraba en Sevilla y estaba dirigida por Pedró Ricaldone; Inspectoría Céltica de Santiago el Mayor, cuyo jefe provincial era Ernesto Oberti y su sede estaba en Madrid-Atocha; y la Inspectoría Tarraconense de Nuestra Señora de la Merced, su sede estaba en Barcelona al mando de Antonio Aime. Se puede considerar que este período supone el asentamiento de la obra salesiana en España, quedándose concluido en 1902 (Alberdi, 1994).

A Ricaldone le sucedieron otros inspectores provinciales, que continuaron la ampliación de la orden. Durante una década la congregación sufrió los avatares políticos y sociales, especialmente con la «Ley del Candado», que disminuía el despliegue normal de las actividades de la congregación, al suprimir las comunidades con menos de I2 socios. Sin embargo, la actividad de la congregación ya estaba consolidada y en I9I2 estaban en funcionamiento centros de enseñanza popular en I4 ciudades españolas (Cárcel, 1979). Posteriormente se siguieron fundando casas en Alcalá de Guadaira y Arcos de la Frontera en 1919, y en Las Palmas de Gran Canaria, Fuentes y Pozoblanco en 1929. Y en cuanto a las escuelas profesionales se fueron estableciendo en Cádiz (I905), Madrid (1918), Las Palmas de Gran Canaria (1923), Pamplona (1927) y Bilbao-Deusto (1938) (Martín González, I980 y i98r; Lenti, 20I2a; Valentini, 1975).

\section{Cronología comparada de la expansión salesiana}

En este apartado presentamos de forma gráfica la evolución de la labor socioeducativa de la obra salesiana en América y en España. Con el siguiente cuadro cronológico pretendemos aportar una visión contrastada de los distintos episodios más significativos de la orden en sus inicios.

\begin{tabular}{|r|l|l|}
\cline { 2 - 3 } \multicolumn{1}{l|}{} & \multicolumn{1}{|c|}{ AMÉRICA } & ESPAÑA \\
\hline I875 & $\begin{array}{l}\text { Cagliero llega a Buenos Aires para ocuparse de } \\
\text { los inmigrantes italianos. Fagnano, en S. Nicolás } \\
\text { de los Arroyos, funda un colegio, un oratorio y } \\
\text { una capilla. } \\
\text { Bodrato crea en Buenos Aires la Escuela de Artes } \\
\text { y Oficios. } \\
\text { Lasagna funda en Montevideo un colegio y un } \\
\text { instituto de Meteorología. }\end{array}$ & \\
\hline I877 & $\begin{array}{l}\text { Se abre un colegio en La Plata. } \\
\text { 2I-VI-I879 }\end{array}$ & $\begin{array}{l}\text { Mons. Espinosa, Botta y Costamagna llegan a la } \\
\text { Patagonia. }\end{array}$ \\
\hline I5-XII-I879 & $\begin{array}{l}\text { Un grupo de salesianos salen de Buenos Aires ha- } \\
\text { cia la Patagonia. }\end{array}$ & \\
\hline I880 & Los salesianos se instalan en Las Piedras. & Cagliero llega a Utrera. \\
\hline I6-II-I88I & & \\
\hline
\end{tabular}


LA LABOR SOCIOEDUCATIVA DE LAS MISIONES SALESIANAS EN AMÉRICA Y ESPAÑA

EN EL SIGLO XIX Y LOS ALBORES DEL SIGLO XX

VICENTE LLORENT BEDMAR Y VICENTE J. LLORENT GARCÍA

\begin{tabular}{|c|c|c|}
\hline & AMÉRICA & ESPAÑA \\
\hline I88I & $\begin{array}{l}\text { Se crea la casa de Paysandú en los nuevos territo- } \\
\text { rios de Uruguay. }\end{array}$ & \\
\hline 1882 & & $\begin{array}{l}\text { Se funda el colegio de S. Diego. } \\
\text { Se abre el asilo de niños huérfanos de S. Barto- } \\
\text { lomé (Málaga). }\end{array}$ \\
\hline I883 & $\begin{array}{l}\text { Patagonia: } 5.328 \text { indios bautizados, creación de un } \\
\text { colegio en los nuevos territorios. } \\
\text { Se abre una casa en Niteroi (Brasil). } \\
\end{array}$ & \\
\hline 1885 & & Se inauguran los talleres de Sarriá. \\
\hline 1886 & $\begin{array}{l}\text { Creación de una escuela y una parroquia en São } \\
\text { Paulo. }\end{array}$ & $\begin{array}{l}\text { D. Bosco visita Barcelona. } \\
\text { Se abre el colegio del Carmen, con las secciones } \\
\text { de educación. }\end{array}$ \\
\hline I 887 & $\begin{array}{l}\text { Fagnano se establece en Punta Arenas. } \\
\text { Tomatis crea en Chile un colegio, talleres y un } \\
\text { oratorio. }\end{array}$ & \\
\hline I888 & Los salesianos llegan a Quito. & \\
\hline De I888 a I890 & Se interrumpe la salida de misioneros salesianos de & ebido a la muerte de D. Bosco. \\
\hline 1890 & $\begin{array}{l}\text { Bogotá: colegio de formación profesional (León } \\
\text { XIII) y atención sanitaria a los leprosos. } \\
\text { Nueva casa en Lorena (Brasil). }\end{array}$ & $\begin{array}{l}\text { Escuela Popular de S. José de Rocafort (Barce- } \\
\text { lona). }\end{array}$ \\
\hline I89I & $\begin{array}{l}\text { Se crea en Lima una escuela de formación profe- } \\
\text { sional (FP) y un oratorio. } \\
\text { Empieza la guerra civil chilena. }\end{array}$ & $\begin{array}{l}\text { Escuela de Agricultura de S. Isidoro (Gerona). } \\
\text { Escuelas populares en Santander. }\end{array}$ \\
\hline 1892 & $\begin{array}{l}\text { Se abre una escuela de Fp en México. Y se extien- } \\
\text { den por otras regiones mexicanas. }\end{array}$ & $\begin{array}{l}\text { Oratorio de Sevilla/Trinidad. De él surgirá una } \\
\text { escuela de Fp y un colegio de educación secun- } \\
\text { daria. }\end{array}$ \\
\hline 1893 & $\begin{array}{l}\text { Fagnano va a Tierra de Fuego. Misión de la Can- } \\
\text { delaria para la instrucción de los indios. }\end{array}$ & $\begin{array}{l}\text { Se abre la casa de Rialp y el colegio del Arenal } \\
\text { (Vigo). } \\
\text { Rinaldi consigue el reconocimiento oficial de la } \\
\text { orden por parte del Gobierno español. }\end{array}$ \\
\hline 1894 & $\begin{array}{l}\text { Creación de escuelas de FP en Venezuela (Caracas, } \\
\text { S. Rafael de Maracaibo y Valencia). }\end{array}$ & Oratorio de S. Enrique (Málaga). \\
\hline 1895 & & $\begin{array}{l}\text { Casa de S. Viceng deis Horts (primer noviciado } \\
\text { salesiano en España). }\end{array}$ \\
\hline I896 & $\begin{array}{l}\text { Fundación de dos escuelas de FP en Bolivia (La } \\
\text { Paz y Sucre). } \\
\text { Se crea una escuela de FP en Asunción. } \\
\text { Finaliza la guerra civil chilena. } \\
\text { Los salesianos de Ecuador son acusados de ma- } \\
\text { niobras antigubernamentales. } \\
\end{array}$ & $\begin{array}{l}\text { Oratorio de Béjar (Salamanca). } \\
\text { Escuela Primaria de Carmona. } \\
\text { Escuela Primaria de Baracaldo. } \\
\text { Escuela de Écija. }\end{array}$ \\
\hline 1897 & $\begin{array}{l}\text { Se abre en El Salvador una escuela de FP agrícola } \\
\text { y un orfanato. } \\
\text { Nueva casa salesiana en Arequipa. En EE. UU. } \\
\text { prestan ayuda a los inmigrantes italianos con cla- } \\
\text { ses de inglés y buscándoles trabajo a los recién } \\
\text { llegados. }\end{array}$ & \\
\hline
\end{tabular}


LA LABOR SOCIOEDUCATIVA DE LAS MISIONES SALESIANAS EN AMÉRICA Y ESPAÑA

EN EL SIGLO XIX Y LOS ALBORES DEL SIGLO XX

VICENTE LLORENT BEDMAR Y VICENTE J. LLORENT GARCÍA

\begin{tabular}{|c|c|c|}
\hline & AMÉRICA & ESPAÑA \\
\hline I898 & Nuevas casas en Cuzco y Piura. & Colegio de S. Antonio (Valencia). \\
\hline 1899 & & $\begin{array}{l}\text { Casas salesianas en Montilla (Córdoba). } \\
\text { Oratorio en Madrid-Atocha. }\end{array}$ \\
\hline 1900 & $\begin{array}{l}25 \text { aniversario de los salesianos en Buenos Aires. } \\
\text { Congreso Internacional }\end{array}$ & \\
\hline 1902 & $\begin{array}{l}\text { Albera consigue calmar el carácter belicoso de los } \\
\text { jíbaros ecuatorianos. }\end{array}$ & $\begin{array}{l}\text { Escuela de S. Francisco de Sales (Córdoba). } \\
\text { División de la península Ibérica en cuatro ins- } \\
\text { pectorías. } \\
\text { Oratorio de Santa Teresa de Ronda. } \\
\end{array}$ \\
\hline 1905 & $\begin{array}{l}\text { Se crea una Escuela Agrícola en Rodeo del Medio. } \\
\text { Nuevas casas en Buenos Aires y Córdoba (Ar- } \\
\text { gentina). }\end{array}$ & $\begin{array}{l}\text { Durante los 1902 y igi2 la situación es especial- } \\
\text { mente difícil para la orden. Las nuevas fundacio- } \\
\text { nes escaseaban debido a los avatares históricos, } \\
\text { fundamentalmente a los problemas regionalistas, } \\
\text { sociales y religiosos. }\end{array}$ \\
\hline I9IO & & $\begin{array}{l}\text { "Ley del Candado», que disminuía el despliegue } \\
\text { normal de las actividades de la congregación, al } \\
\text { suprimir las comunidades con menos de i2 socios. }\end{array}$ \\
\hline
\end{tabular}

\section{Conclusiones}

Una vez estudiados los orígenes de la labor salesiana en América y España, hemos comprobado que, aunque existen elementos similares en ambos inicios, son apreciables los rasgos específicos que los diferencian, destacando los siguientes:

- Las expediciones americanas se suceden de manera más continuada en el tiempo, y son anteriores a las españolas (I875, I876, I877, I879). Las españolas, al menos en el primer decenio, no son tan frecuentes.

- En España, las fundaciones de Málaga y Sarriá surgen porque parte de la comunidad salesiana de Utrera se traslada a estos lugares. En cambio, en América la mayoría de los salesianos procedían de Italia, por ejemplo, la segunda expedición americana (1876) que contaba con veintitrés religiosos procedentes de Italia. Estos y otros datos similares parecen indicar que en un principio se tenía un mayor interés en las expediciones americanas que en las españolas (Lenti, 20I2a).

- En España la congregación centra sus esfuerzos en educación primaria, secundaria y formación profesional. En América, su labor es más amplia: en Buenos Aires se encargan de la transformación religiosa de los inmigrantes italianos; en Uruguay, Lasagna logra la adaptación del cultivo de la vid y crea un instituto de meteorología; se trabaja con indios pampas, jíbaros, tehuelches... que vivían en estado nómada o seminómada, etc. Una vez promulgada la ley de emancipación de los hijos de los siervos se crean talleres de trabajo para la formación de los jóvenes. En EE. UU. se organizan clases nocturnas de inglés para los inmigrantes, se busca trabajo a los recién llegados, etc.

- Tanto en América como en España, en un momento determinado, las instituciones políticas son conscientes de la importancia de la orden salesiana. En España, 
el rey Alfonso XII felicita a Juan Branda, y los liberales se declaran defensores de los salesianos por la ayuda que éstos prestan al pueblo. Lo mismo sucedió en distintas ciudades americanas, como ejemplo de tal situación señalaremos que en 1937 el partido socialista chileno, que se encontraba en el poder, tributó un homenaje a la congregación, al que se adhirió la Cámara de Diputados.

Pero también los salesianos fueron víctimas de los avatares políticos, como en el caso de la República española, en la que fueron desmanteladas muchas «casas» y algunos salesianos se vieron obligados a huir. En Ecuador, el general Alfaro acusó en 1896 a los religiosos de maniobras antigubernamentales.

- En América, el interés por explorar nuevas regiones es un elemento esencial. Se penetra en territorios habitados por tribus «salvajes», hasta ese momento desconocidos por el hombre «civilizado». Así, en I878 se intenta llegar a Patagonia por el mar, pero las inclemencias climáticas hacen fracasar este primer intento, que se consigue un año después. Fagnano en 1886, aprovechando una misión exploratoria del Gobierno argentino a Isla Grande, acompañó al ejército, en busca de un lugar más idóneo para crear una futura misión (Nicoletti y Barelli, 20Io).

- Las fundaciones españolas se deben en su mayoría al patrocinio de la nobleza o de la alta burguesía (marqués de Casa Ulloa, Dorotea Chopitéa, conde de la Casa Galindo, marquesa de Mos, etc.). En cambio, las fundaciones en tierras americanas se deben a peticiones de los distintos gobiernos, que preocupados por la inexistencia de Escuelas de Artes y Oficios y Formación Profesional en sus países (Argentina, Brasil, Perú, etc.) solicitan la ayuda de la orden. A este respecto conviene no olvidarse de que en estos países estaban surgiendo por entonces ciertas actividades de tipo agrícola e industrial.

- En América los centros de enseñanza eran estatales, mientras que en España eran privados. Los centros no gratuitos que existían en nuestro país constituían un caso atípico de la congregación, ya que los salesianos siempre habían orientado su obra hacia las clases humildes.

- En el segundo período la obra misionera salesiana en América va a la par de las actividades realizadas en Europa, si bien en América, además de ampliar las instituciones ya existentes, los salesianos se establecieron en nuevos territorios.

- En cuanto a los personajes es muy difícil encontrar salesianos que estén presentes en América y en España. Es quizás Juan Cagliero uno de los pocos salesianos presentes en ambos lugares, debido a que D. Bosco le confiaba muy especialmente las primeras fundaciones y porque además era uno de los pocos salesianos que conocía y hablaba el español.

Se puede afirmar que, a causa de las distintas características históricas, económicas, políticas y culturales de España y América, la obra salesiana tiene rasgos peculiares en cada uno de estos territorios. Sin embargo, en ambos tienen un tronco común: la aplicación del sistema preventivo, nacido en el Oratorio de Turín, como el primer y más importante principio educativo por el que se debían regir (Alberdi, 1994; Chávez, 2006). 
LA LABOR SOCIOEDUCATIVA DE LAS MISIONES SALESIANAS EN AMÉRICA Y ESPAÑA

EN EL SIGLO XIX Y LOS ALBORES DEL SIGLO XX

VICENTE LLORENT BEDMAR Y VICENTE J. LLORENT GARCÍA

Es destacable el papel pedagógico de los salesianos como iniciadores y difundidores de la formación profesional por todo el mundo ${ }^{7}$. Hecho que constituye la principal aportación de la orden en materia educativa en España, destacando los primeros centros de formación profesional creados en Barcelona, Málaga, Madrid y Sevilla cuando aún no existía ninguna legislación a este respecto. Dicha legislación no fue elaborada hasta 1928, cuando se creó el primer estatuto de Formación Profesional, que no se aplicaría hasta 1955, con el entonces ministro de Educación Joaquín Ruiz-Giménez, por entonces la congregación contaba ya con once escuelas para la formación de jóvenes aprendices en nuestro territorio (Canals y Martínez, 1978; Toro, 2008).

Por otra parte, resaltamos en América la labor pedagógica salesiana, unida a la exploración de nuevos territorios, con la iniciación y expansión de diferentes instituciones educativas, ofreciendo una red que facilitaría la oferta formativa en lugares y poblaciones con grandes carencias de infraestructuras (Miranda, 2005).

Desde sus comienzos, el éxito socioeducativo del programa académico salesiano ha radicado en su base pedagógica, en línea con las más modernas tendencias europeas. Los diferentes hitos pedagógico-religiosos hacen constar que los salesianos iniciaron todo un engranaje educativo para facilitar la inserción sociolaboral de los jóvenes, articulando el conocimiento científico junto con una enseñanza práctica, promoviendo la mejora de las condiciones socioeconómicas y educativas de los alumnos en América y España.

\section{Bibliografía}

Alberdi, Ramón: «Educación institucional: la escuela confesional católica; instituciones educativas salesianas», en Delgado CRIAdo, Buenaventura (coord.): Historia de la Educación en España y América, vol. 3 (La educación en la España Contemporánea), Madrid, Morata, Fundación Santa María, 1994, pp. 725-730.

Avanzini, Guy: «La pedagogía de San Juan Bosco en su siglo», en Prellezo, José Manuel (dir.): D. Bosco en la historia. Actas del Primer Congreso Internacional de Estudios sobre San Juan Bosco, Roma/Madrid, LAs/css, 1990, pp. 29I-298.

Bastarrica, Ramón: Los salesianos en Santander, Pamplona, Ediciones Don Bosco, I98I.

Belza, Juan E.: Sueños patagónicos, Buenos Aires, Instituto de Investigación Histórica Tierra del Fuego, 1982.

Blengino, Vanni: La zanja de la Patagonia. Los nuevos conquistadores: militares, científicos, sacerdotes, escritores, Buenos Aires, Fondo de Cultura Económica, 2005.

Borrego, Jesús: «Originalidad de las misiones patagónicas», en Prellezo, José Manuel (dir.): D. Bosco en la historia. Actas del Primer Congreso Internacional de Estudios sobre San Juan Bosco, Roma/Madrid, LAs/css, I990, pp. 29I-298.

Bosco, Teresio: D. Bosco. Una Biografía Nueva, Caracas, Librería Editorial Salesiana, I994, p. 155 .

Braido, Pietro: Prevenir, no reprimir: el sistema educativo de Don Bosco, Madrid, ccs, 2010.

Braido, Pietro y Calonghi, Luigi: D. Bosco Educador, Roma, Pas, i96o.

Aunque son los Hermanos de las Escuelas Cristianas los creadores de las llamadas Escuelas Lancasterianas (1820) donde se impartían clases nocturnas para artesanos. 
LA LABOR SOCIOEDUCATIVA DE LAS MISIONES SALESIANAS EN AMÉRICA Y ESPAÑA EN EL SIGLO XIX Y LOS ALBORES DEL SIGLO XX

VICENTE LLORENT BEDMAR Y VICENTE J. LLORENT GARCÍA

Braido, Pietro; Simoncelli, Pietro y Gianola, Pietro y otros: Educar (tomo i), Salamanca, Ediciones Sígueme, 1967.

Bravo y LiÑán, Francisco: Carta dirigida a la congregación salesiana, Sevilla, I4 de febrero de I888.

Canals Pujol, Juan y Martínez Azcona, Antonio: S. Juan Bosco, Obras Fundamentales, Madrid, BAG, 1978.

CÁrCel OrTí, Vicente: La Iglesia en la España contemporánea (I808-1975), Madrid, Edica, I979.

Cantero Cuadrado, Pedro: En torno a la F.P. de las Juventudes Obreras Españolas, Huelva, Ateneo Salesiano, I958.

Chávez, Pascual: «Educación y ciudadanía. Formar “salesianamente” al ciudadano», Foro Educacional, io (2006), pp. 15-39.

Coello De la Rosa, Alexandre: «Los jesuitas y las misiones de frontera del alto Perú: Santa Cruz de la Sierra (1587-1603)», Revista Complutense de Historia de América, 33 (2007), pp. I5I-I75.

Entraigas, Raúl A.: El apóstol de la Patagonia, Rosario, Editorial Apis, 1955.

Estrada, María Alejandra: «¿Mesianismo salesiano en Patagonia septentrional? Último cuarto del siglo xIx, pueblo General Roca», Revista Española de Antropología Americana, 4I (I) (20II), pp. 97-II6.

Fierro, Rodolfo: Pedagogía Social de D. Bosco, Madrid, Consejo Superior de Investigaciones Científicas, 1949 .

Gómez Bajuelo, Gil: «El colegio de Nuestra Señora del Carmen en Utrera, primera casa salesiana que se fundó en Europa», $A B C$-Sevilla, ,o de julio de 1934.

Hoz, Francisco: Resumen de la Historia Salesiana I815-1965, Sevilla, Sociedad Salesiana, 1965.

Lemoyne, Juan Bautista y Fierro Torres, Rodolfo: Vida de S. Juan Bosco, Madrid, Sociedad Editora Ibérica, 1957.

Lenti, Arthur: D. Bosco: Historia y carisma 3. Apogeo: De Turin a la gloria de Bernini, Madrid, CCS, 20I2a.

Lenti, Arthur: D. Bosco: Historia y carisma 2. Expansión: De Valdocco a Roma (1850-1875), Madrid, cCs, 20I2b.

López Torres, Lorena: «Sacramentos e identidad en la última canoa. Travesía de un Kaweskar al borde del mapa», Revista Chilena de Literatura, 80 (2011), pp. 185-202.

Martín GonzÁlez, Ángel: Origen de las misiones salesianas, Guatemala, Instituto Teológico Salesiano, 1978.

Martín González, Ángel: Los salesianos de Utrera en España, Sevilla, Inspectoría Salesiana de Sevilla, I98I, p. I50.

Martínez Azcona, Antonio; Calero, Antonio y otros: D. Bosco, cien años en España, Madrid, Central Catequística Salesiana, ig8o.

Miranda, Ángel: «La actividad educadora institucional: órdenes, congregaciones y asociaciones eclesiales masculinas dedicadas a la educación y a la enseñanza: los salesianos», en Bartolomé Martínez, Bernabé (coord.): Historia de la acción educadora de la Iglesia en España: Edad contemporánea, Madrid, Biblioteca de Autores Cristianos, 2005, pp. 472-49I.

Nicoletti, María Andrea: La configuración del espacio misionero: Las misiones coloniales en la Patagonia Norte, 24, 1998, pp. 87-II2.

Nicoletti, María Andrea: «La conflictiva incorporación de la Patagonia como tierra de misión (1879-1907)», Boletín Americanista, 54 (2004), pp. I45-166.

Nicoletti, María Andrea: «Evangelizar y educar a los indígenas de Patagonia: conceptos claves de Giovanni Bosco y sus misioneros salesianos (mediados del siglo xix a principios del siglo xx)», Revista Espacios. Historia Política y Educación, 4 (2005), pp. 92-106.

Nicoletti, María Andrea: «Fuego cruzado: la polémica sobre la conquista y el genocidio patagónico en la congregación salesiana», en Segundas Jornadas de Historia de la Patagonia, Roca, Universidad Nacional del Comahue, 2006, pp. I-2o. 
Nicolettr, María Andrea: «Los salesianos y la conquista de Patagonia: desde D. Bosco hasta sus primeros textos escolares e historias oficiales", Revista Tefros, 5 (2007/2), pp. I-24.

Nicolettr, María Andrea: Indígenas y misioneros en Patagonia, Buenos Aires, Continente, 2008.

Nicoletti, María Andrea y Barelli, Ana Inés: «"Hijos de Dios y miembros de la Santa Madre Iglesia": adoctrinar y bautizar en la Patagonia de fines del siglo XIX y principios del XX», Revista Cultura y Religión, IV (2010/2), pp. I2O-I46.

Rogier, Louis J.; Aubert, Raphä̈l; Aubert, Roger; Bertier de Sauvigny, Guillaume de y Knowles, David: Nueva historia de la Iglesia. Volumen 5. La Iglesia en el mundo moderno: I848 al Vaticano II, Roma, Ediciones Cristiandad, I977, p. II7.

Santiago, Diego María: Carta dirigida a D. Bosco, Utrera, 2I de noviembre de 1885.

Saranyana, Josep-Ignas (dir.): Teología en América Latina. Vol. II/2. De las guerras de independencia hasta finales del siglo XIX (I8I0-I899), Madrid/Fráncfort, Iberoamericana/Vervuert, 2008, pp. 139, 203 y 615.

Schlossarek, Volkswirt Sebastian: La abolición de la esclavitud en Brasil, Múnich, Editorial GRIN GmbH, 2006, p. 9.

Schwaiger, Georg: La vida religiosa de la A a la Z. Desde los orígenes hasta nuestros días, Madrid, Ed. San Pablo, 1998, p. 35.

SDB: La familia salesiana, sitio web oficial de la sociedad los Salesianos de Don Bosco (20I2). Consultado en: http://www.sdb.org/es/.

Sinistrero, Vincenzo: Scuola e Formazione professionale del mundo, Roma, Ateneo Salesiano, 1963.

Teobaldo, Mirta y Nicoletti, María Andrea: «Representaciones sobre la Patagonia y sus habitantes originarios en los textos escolares: I886-I940», Quinto Sol, II (2007), pp. I69-I94.

Toro, Abraham: «Aproximación a la historia social e institucional del centenario colegio D. Bosco de Valencia», Heurística: Revista Digital de Historia de la Educación, 9 (2008), p. I-I3. Consultado en http://www.saber.ula.ve/bitstream/I23456789/21095/5/articuloi.pdf.

Utrera. Archivo de la Casa de Utrera (ACu): Crónica de las Casas de Utrera y Málaga, pp. 4 y 5.

Valentini, Eugenio: Cronología de las misiones salesianas, Roma, Librería Ateneo Salesiana, 1975.

Valiente Moreno, Francisco Javier: «D. Bosco y la comunicación educativa», Educación y Futuro, 24 (20II), pp. IOI-II5.

Wirth, Morano: D. Bosco y los Salesianos, Barcelona, Ediciones D. Bosco, I97I.

Wost, Hugo: Don Bosco y su tiempo, Madrid, Ed. Palabra, 2002. 